\title{
Characterization of a brain tumor cell line established from transgenic mice expressing the vasopressin SV-40 T antigen
}

\author{
Sung Hyun $\mathrm{Kim}^{1,3}$, Myoung Ok Kim${ }^{1}$, \\ Sang Ryeul Lee ${ }^{1}$, Kil Soo Kim ${ }^{2}$, \\ Tae-Hoon Lee ${ }^{4}$, Hoon Taek Lee ${ }^{3}$, \\ Ji Hong $\mathrm{Ha}^{1}$, Tae Yoon $\mathrm{Kim}^{5 *}$ \\ and Zae Young Ryoo, ${ }^{1,6 *}$
}

\author{
${ }^{1}$ School of Life Science and Biotechnology \\ ${ }^{2}$ Department of Veterinary Medicine \\ College of Veterinary Medicine \\ Kyungpook National University \\ Daegu 702-701, Korea \\ ${ }^{3}$ Department of Animal Science \\ Graduate School of Konkuk University \\ Seoul 143-701, Korea \\ ${ }^{4}$ Department of Oral Biochemistry \\ College of Dentistry, Chonnam National University \\ Gwangju 500-757, Korea \\ ${ }^{5}$ Department of Immunobiology and Dermatology \\ College of Medicine, Catholic University \\ Seoul 137-040, Korea \\ ${ }^{6}$ Corresponding author: Tel, 82-53-950-7361; \\ Fax, 82-53-943-6925; E-mail, jaewoong64@hanmail.net \\ *These authors contributed equally to this work.
}

Accepted 23 February 2006

Abbreviations: FISH, fluoresent in situ hybridization; SV, simian virus; VP, vasopressin

\begin{abstract}
We previously reported that transgenic mice produced with a transgene consisting of the SV40 T antigen and vasopressin without the 3'-flanking region exhibit brain tumors and lymphoma. In this study, transgenic mice were produced with the fusion gene containing the SV40 T antigen and the whole vasopressin gene with the 3'-flanking region. Six transgenic mice were generated, five which died after 2-6 weeks. The remaining founder mouse was investigated for fusion gene expression and tumor progression at the age of 6 weeks. Brain tumor cells were characterized for phenotypes and transgene expression. During in vitro cell cultures, the phenotypic appearances at 10,20 , and 30 passages were as a uniform monolayer with similar growth rates. The site of SV40 T antigen integration was
\end{abstract}

in the A2 region of chromosome 11, and SV40 T antigen was expressed at the same level in cells of both earlier and later passages. Thirty passages were probably insufficient to reach crisis and immortalization. These cells enriched brain tumor cell compositions with astrocytes and neuronal cells.

Keywords: astrocyte cell; brain tumor cell; neuronal cell; transgenic mice; vasopressin

\section{Introduction}

We previously reported the generation of transgenic mice via microinjection of the fusion gene (pVPSV.IGR2.1) consisting of the SV40 T antigen and mouse vasopressin (VP) without the 3'-flanking region (Lee et al., 2003). Of these mice, $21 \%$ developed brain tumors at 5 weeks and the remaining mice developed brain tumors after 24 weeks. Histological analysis of the transgenic mice revealed primitive neuroectodermal tumors (PNET) in the brain with lymphoma in the spleen and lymph nodes.

The PNETs of the central nervous system are a family of brain tumors and embryonic malignant tumors that account for $20 \%$ of all midbrain tumors in children. These tumors are characterized by primitive histological features resembling neuroepithelial stem cells from the embryonic neural tube or immature progeny (Lee et al., 2003). pVPSV.IGR2.1 transgenic mice provide a valuable mouse model system for investigating PNET tumorigenesis in the brain and lymphoma in the lymph nodes and spleen. However pVPSV.IGR2.1 transgenic mice died after 24 weeks with tumors in the brain so this model is not useful for study of tumor progression.

The regulatory regions for VP gene expression are still unclear and the IGR domains contain various transcription binding sites that control tissuespecific expression and may have functions that have yet to be elucidated (Ratty et al., 1996; Jeong et al., 2001). SV40 is a DNA tumor virus that produces oncogenicity in vivo by inducing brain tumors in rodents (Tognon et al., 1996). Although the SV40 T antigen and derived cell lines exhibit clonal nonrandom chromosomal abnormalities, little is known about the event that causes chromosomal instability and rearrangement (Tognon et al., 1996). In order to study tumorigenesis that occurs in the 
central nervous system, a cell line that resembles astrocytes and neuronal cells is required.

We established a brain tumor cell line from transgenic mice for tumor genetics and physiology studies. This is a novel model system in which the molecular mechanism of cellular differentiation associated with the central nervous system can be analyzed. We generated pVPSV.IGR2.1 transgenic mice and established a cell line that was characterized by phenotype, growth rate, and expression of astrocytes and neuronal markers.

\section{Materials and Methods}

\section{Preparation of the VP transgene}

The transgene plasmid pVPSV.IGR3.6 was initially constructed by replacing the chloramphenicol acetyl transferase (CAT) reporter gene with the SV40 T antigen gene (Jeong et al., 2001). The transgene in the pSE280 vector (Invitrogen, Carlsbad, CA) contains the $3.6 \mathrm{~kb}$ IGR section possessing the mouse VP gene of the 5'- and 3'-flanking regions, including all exons and introns. The SV40 $\mathrm{T}$ antigen gene (ACTT, Manassas, VA) was fused at exon III (Figure 1). The SV40 T antigen gene was prepared by PCR amplification and Not I digestion of the PCR product, which was inserted into the Not I site of the transgene plasmid. The primers used were 5'- ATA TAG CGG CCG CGC AAA GAT GGA TAA AGT TTT AAA CAG -3' and 5'- ATT ATG CGG CCG CAT TCA TTT TAT GTT TCA GGT TC -3'.

\section{Production and identification of transgenic mice} Linear transgene DNA fragments containing the Bam HI/Eco47 III fragment that was excised from the pVPSV.IGR3.6 plasmid were purified in a $10-40 \%$ sucrose gradient, then dialyzed against $10 \mathrm{mM}$ Tris- $\mathrm{Cl}(\mathrm{pH} 7.4)$ and $0.1 \mathrm{mM}$ EDTA. Transgenic mice (BCF1: $\mathrm{C} 57 \mathrm{BL} / 6 \times \mathrm{C} 3 \mathrm{H}$ hybrid) were produced using microinjection of transgenes at a concentration of $3 \mu \mathrm{g}$ according to standard protocols (Ryoo et al.,
2001; Lee et al., 2003). Following microinjection, viable conceptuses were transferred to ampullae of pseudopregnant ICR mice. The presence of the transgene was determined in tail genomic DNA through PCR and southern blot analysis.

\section{Establishment of a cell line}

Primary cell cultures from midbrain tumors of one of the transgenic mice were prepared as a source of brain tumor cells. Tissue sections of midbrain tumors were minced and dispersed at $37^{\circ} \mathrm{C}$ for $30 \mathrm{~min}$ in Hanks Balanced Salt solution containing $10 \mathrm{mg} / \mathrm{ml}$ collagenase (Cooper Biomedical, Malvern, PA) and $10 \mu \mathrm{g} / \mathrm{ml}$ DNAse I (Sigma, St. Louis, MO). The cells were washed in PBS and subsequently plated in Dulbecco's Modified Eantigenle Medium (Gibco Laboratories, Grand Island, NY) that consisted of $10 \%$ fetal calf serum (Hycolon Laboratories, Lugan, UT), $4.5 \mathrm{mg} / \mathrm{ml}$ glucose, $100 \mathrm{U} / \mathrm{ml}$ penicillin, and 0.1 $\mathrm{mg} / \mathrm{ml}$ streptomycin (Sigma, St. Louis, MO). Floating and weakly adherent cells were transferred to fresh plates every 3 days.

\section{SV40 T antigen determined by FISH}

Cultured cells after 30 passages were fixed on silan-coated slides (Fisher Scientific, Pittsburgh, PA) and processed for FISH (Fluorescent In Situ Hybridization) using a digoxigenin-labeled SV40 T antigen DNA probe and a chromosome in situ hybridization kit (Ventana Medical Systems, Tucson, AZ) on an automated in situ hybridization instrument (Ventana Gen II, Ventana Medical Systems). The amount of probe hybridization mixture that was used was calculated relative to the target area $(10 \mathrm{ml}$ of probe mixture per $484 \mathrm{~mm}^{2}$ ) of fixed cell area). Denaturation was performed at $69^{\circ} \mathrm{C}$ for 5 min before slides were incubated overnight at $37^{\circ} \mathrm{C}$ with the hybridization probe. After overnight hybridization and three post-hybridization stringency washes, fluorescence as a labeled antidigoxigenin detection reagent was manually applied to the slide sections at

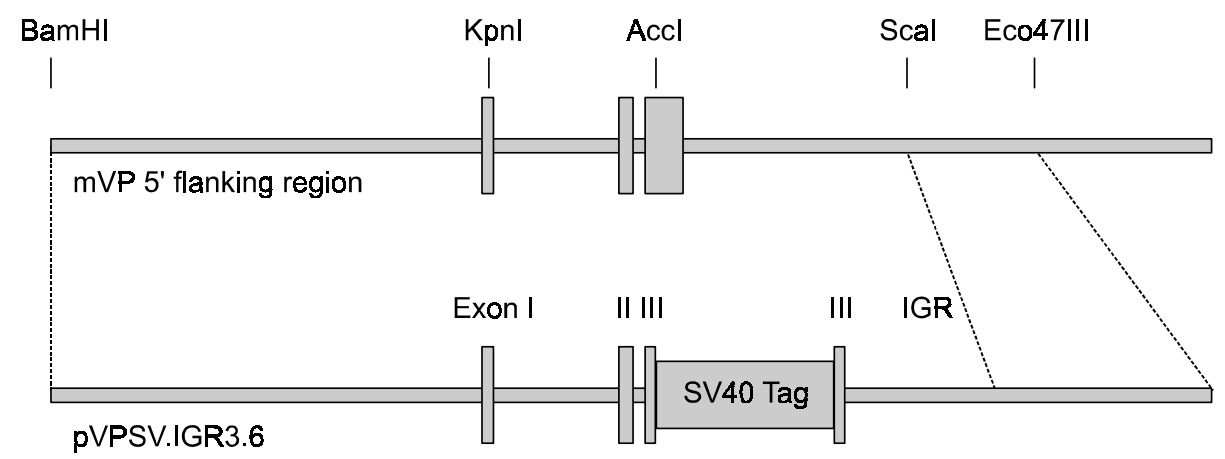

Figure 1. Vasopressin (VP)-transgene constructs. The transgenes contain $3.6 \mathrm{~kb}$ of the IGR consisting of the 5'- and 3'-flanking regions, and also contain all exons and introns of the mouse VP gene. The SV40 T antigen (Tag) was fused at the end of exon III. 
$37^{\circ} \mathrm{C}$ for $28 \mathrm{~min}$. After removing the slides from the instrument, each slide was counterstained with $18 \mathrm{ml}$ of propidium iodide antifade (1:2). Copy numbers for the SV40 T antigen gene were evaluated microscopically (Zeiss Axioskop 50 fluorescence microscope, Carl Zeiss, Thornwood, NY) at a magnification of $\times 100$. Amplification scoring was based on fluorescence. The probe displayed a single fluorescent spot for each SV40 T antigen gene copy. The expected number of SV40 T antigen spots per normal or un-amplified tumor cell was two, or four in dividing cells. A minimum of 100 cells were evaluated for each specimen. Tumors were considered to be amplified for the SV40 T antigen gene when at least 20 cells displayed five or more spots per cell.

\section{Immunoperoxidase cell staining}

Brain tumor cells were cultured on a 6-well plate in a humidified incubator under $5 \% \quad \mathrm{CO}_{2}$ at $37^{\circ} \mathrm{C}$. The cells were washed with PBS and then fixed in $-10^{\circ} \mathrm{C}$ methanol for $5 \mathrm{~min}$. Fixed cells were incubated for $5-10 \mathrm{~min}$ in PBS that contained 0.1 to $1 \%$ hydrogen peroxide to quench the endogenous peroxidase activity. Immunoperoxidase staining required fixed cells to be incubated in a mixture of $1.5 \%$ normal blocking serum in PBS for one hour, followed by incubation with the primary antibody at room temperature for 30 min. After washing with three changes of PBS, each for $5 \mathrm{~min}$, filters the cells were incubated for $30 \mathrm{~min}$ with a biotin conjugated secondary antibody, washed extensively with PBS, then incubated with an avidin biotin enzyme reagent (ABC Staining System, Santa Cruz Biotechnology, Inc., CA).

\section{Western blot analysis}

Homogenized cells were used to determine SV40 T antigen expression in the brain tumor cells. The
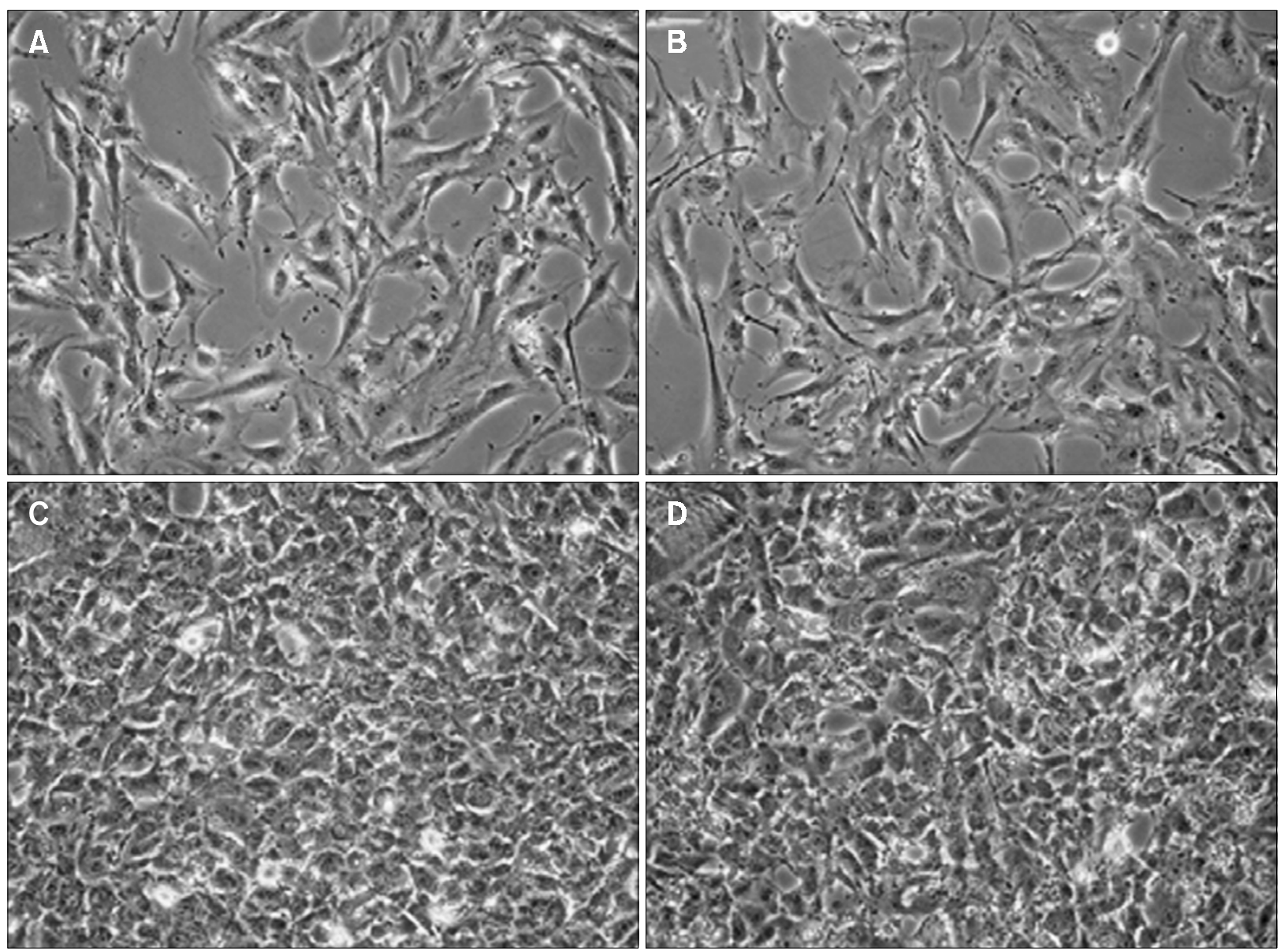

Figure 2. Primary cell cultures from a midbrain tumor of a pVPSV.IGR3.6 transgenic mouse. Brain tumor cells $\left(2 \times 10^{4}\right.$ cell/well) in DMEM supplemented with $10 \%$ FBS were seeded in plates and were incubated at $37^{\circ} \mathrm{C}$ for 3 days. At 10 passages $(A, C)$ and 30 passages (B, D); 1 day culture $(A, B), 3$ day cultures $(C, D) . \times 200$ 
protein concentration levels were determined using a Bio-Rad protein assay kit (Bio-Rad, Hercules, CA) with BSA as a standard. Equal amounts of protein from each cell homogenate were subjected to $8 \%$ SDS-PAGE and then transferred to a nitrocellulose membrane filter. This filter was blocked in Trisbuffered saline containing $5 \% \mathrm{BSA}, 50 \mathrm{mM}$ Tris- $\mathrm{HCl}$ of $\mathrm{pH} 7.5,0.15 \mathrm{M} \mathrm{NaCl}$, and $0.1 \%$ Tween-20 (TBST) at room temperature for $3 \mathrm{~h}$. The filter was then washed with TBST and blotted with a monoclonal antibody against the SV40 T antigen (Pab 101, Santa Cruz Biotechnology, Inc.). The SV40 T antigen was localized using an ELC system (Amersham, Buckinghamshire, UK).

\section{Results}

\section{Characterization of the brain tumor cell line derived from the midbrain tumor}

Tumor tissues that were isolated from the surviving founder transgenic mouse were dispersed and maintained in culture for several months (Figure 2). This resulted in the generation of a novel cell line derived from the midbrain tumor of the pVPSV.IGR3.6 transgenic mouse. The balance between cell proliferation and cell death was maintained for several months (30 passages) without any sign of senescence. It has been reported that SV40 T transformed human bronchial epithelial cells that were cultured for 2 yrs were nontumorigenic, as assayed by s.c. injection of these cells into athymic nude mice (Lu et al., 1998). No tumors resulted when SV40 $\mathrm{T}$ antigen gene transformed cells were injected into nude mice, which suggests that this cell line was still in a premalignant stage (data not

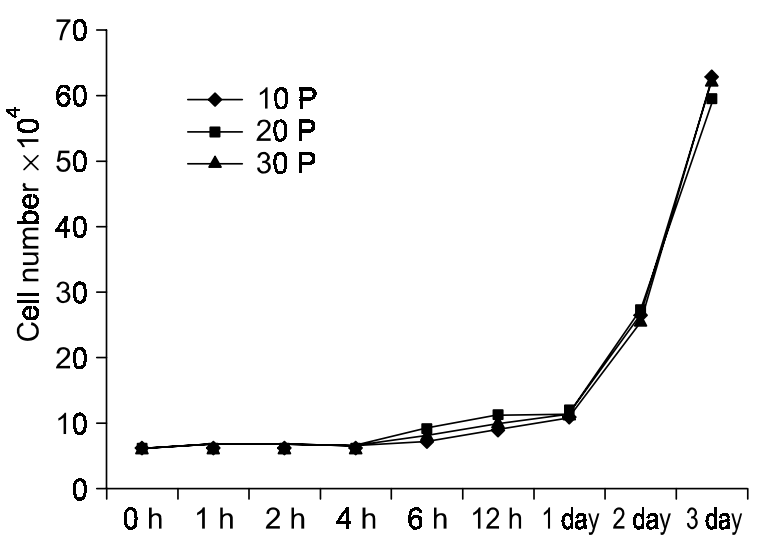

Figure 3. Growth rate assay of the midbrain tumor cell line. At 10, 20, and 30 passages, cells were recovered after $0,1,2,4,6,12,24,48$, and $72 \mathrm{~h}$, and were stained with methyl blue for cell counting using a hemocytometer. P: passage shown). During the development of these features, the morphological appearance of the cells after 10 , 20 , and 30 passages was as a uniform monolayer with a similar growth rate (Figure 2 and 3 ).

\section{SV40 $\mathrm{T}$ antigen determination by FISH}

To determine the chromosomal location of the integrated SV40 T antigen gene, painting fluorescence in situ hybridization (FISH) analysis was performed. Cultured cells after 30 passages were used to produce chromosome spreads that were hybridized with the biotinylated SV40 T antigen probe. The integrated SV40 T antigen gene was localized to chromosome 11, A2 (Figure 4).

\section{Immunoperoxidase cell staining and transgene expression}

The coincidence that the SV40 T antigen transgenic line (at least pVPSV40.IGR3.6) exhibited the same degree of SV40 T antigen expression and genomic stability at all passages is remarkable. It is possible that only SV40 T antigen integration at chromosome $11, A 2$ is necessary for continuous expression of the SV40 $T$ antigen protein and for survival of these cells. After 30 passages, the cells were stained with GFAP (90\% positive cells), then NF150 antibody (10\% positive cells) expression was determined (Figure 5). These midbrain tumor cells expressed the integrated SV40 T antigen genome, based on immunostaining analysis (Figure 6). The degree of protein expression is multi-factional involving transcription, translation, protein stability, and degradation. The SV40 T antigen levels in rapidly growing polyclonal cell lines appear to be regulated primarily
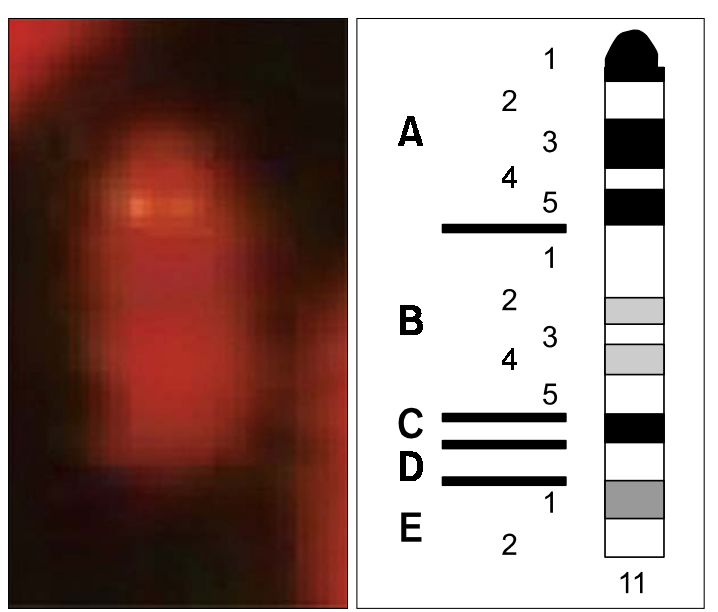

Figure 4. FISH analysis for detection of the SV40 T antigen gene in chromosomes. The yellow bar indicates the site of SV40 T antigen integration, detected on chromosome 11, A2. 

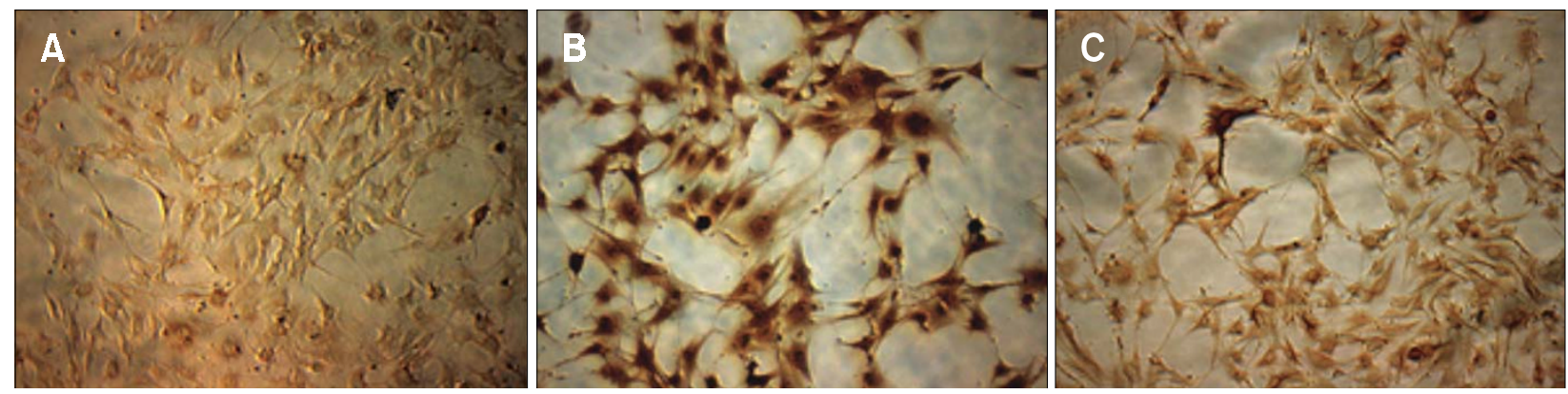

Figure 5. Characterization of cells derived from the midbrain tumor by immunostaining analysis. Cells after 30 passages were stained with GFAP ( $90 \%$ positive cells) and NF 150 antibody (10\% positive cells). (A) control, (B) astrocyte cell - GFAP antibody, (C) neuronal cell - NF150 antibody. $\times$ 200
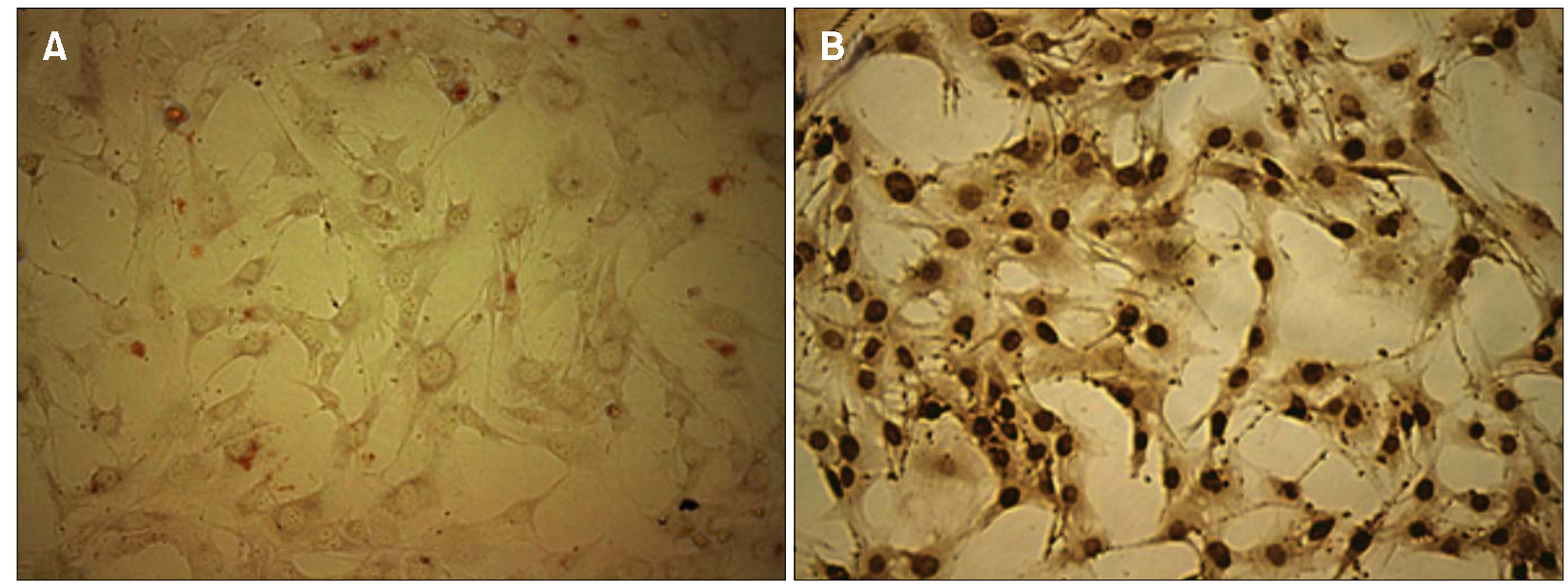

Figure 6. Culture of cells derived from the midbrain tumor. Tumor cells were reacted with the antibody to SV40 T antigen. Brown regions indicate immunoreactivity. (A) control, (B) stained with SV40 T antigen. $\times 200$

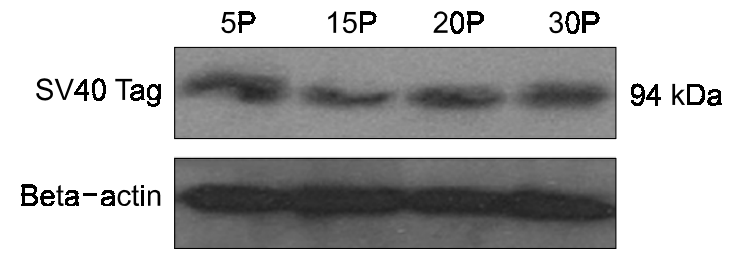

Figure 7. Identification of SV40 T antigen expression in the midbrain tumor cell line. Equally loaded protein samples from each passage of the midbrain tumor cell line were electrophoresed, blotted, and reacted with a monoclonal antibody Pab 101 against the SV40 T antigen. A major band of the expected $94 \mathrm{kDa}$ protein was detected. All passages of the cell line expressed the SV40 T antigen protein. P: passage.

through transcription (Sladek et al., 1992; Dolcetti et al., 2003). The positive results for SV40 T antigen expression in cultured cells after 30 passages revealed that the SV40 T antigen was expressed at the same level in cells of both earlier passages (5) and later passages $(10,20$, and 30$)$, and that the
SV40 $\mathrm{T}$ antigen gene was activated during this culture period (Figure 7).

\section{Discussion}

We generated six transgenic mice by using the vasopressin gene construct to drive the expression of SV40 T antigen (Figure 1), which manifests a transforming potential through probable inactivation of the major cellular tumor suppressor protein p53 (Symonds et al., 1993; McCarthy et al., 1994; Symonds et al., 1994; Seo et al., 2004). Five of the founder mice died between 2 and 6 weeks of age without transmitting the transgene to offspring (Lee et al., 2003). These mice became lethargic and severely dehydrated before death. It is possible that specific expression of the SV40 T antigen in the hypothalamic magnocellular neurons of pVPSV.IGR3.6 transgenic mice may have a deleterious effect on hypothalamic development. VP is synthesized in the 
nuclei of the hypothalamic magnocellular neurons. In this study, however, tumor production was identified in the midbrain and not in hypothalamic-derived cells. The appearance of ectopic tumors in transgenic mice may be due to lack of tissue specificity of the transgene that was used (Montag et al., 1993; Chen et al., 2002).

However, at least two different transcripts for the VP promoter and SV40 T antigen fragments have been expressed through alternate pVPSV.IGR3.6 gene usage and alternative splicing (Lee et al., 2003). An alternate and less likely explanation would be that the VP promoter has nothing to do with tissue-specific expression of the transgene. This is unlikely because the SV40 early gene sequence itself, without an inherent or heterologous promoter element, does not induce tumors of any kind (Hanahan et al., 1985, Messing et al., 1985). Therefore, the coding sequences of the transgenes were examined to determine if they could be normally expressed in the transfected cell lines. Since VP derived cell lines were not available, the VP promoter was replaced with the CMV- $\beta$ universal promoter, then transfected into the neuronal cell line $\mathrm{PC}-12$. The SV40 T antigen was detected in the nucleus of PC-12 neuronal cells by means of immunohistochemistry using a monoclonal antibody (Pab101) against the SV40 $\mathrm{T}$ antigen (data not shown).

The $3.6 \mathrm{~kb}$ IGR fragment (designated pVPSV.IGR3.6) included a $3.6 \mathrm{~kb}$ section of the 3 ' flanking region that was integrated in chromosome $11, \mathrm{~A} 2$. Histological studies of the tumors revealed PNETs in the midbrain, and a high SV40 $\mathrm{T}$ antigen protein expression level was also identified in the tumors by immunohistochemistry and Western blotting (Figure 6 and 7). These results suggest that SV40 T antigen expression under the control of the VP gene can affect morphological changes in the transgenic brain that, in turn, eventually cause PNETs. PNETs of the central nervous system are a family of brain tumors that account for $20 \%$ of pediatric midbrain tumors (Park et al., 1983). They are characterized by primitive histological features resembling neuroepithelial stem cells from the embryonic neural tube or immature progeny. Therefore, pVPSV.IGR3.6 mice provide a model system for investigating PNET tumorigenesis in the midbrain. This midbrain tumor cell line is composed of astrocytes and neuronal cells.

We have explored the relationship between SV40 $\mathrm{T}$ antigen expression as a function of cell growth, and cell differentiated morphologies of SV40 T antigen established mouse astrocytes and neuronal cells. These cells may depend upon expression of the $T$ antigen for cell growth and cell differentiated morphologies (Figure 2 and 3 ). This result suggests that the inactivated $\mathrm{pRb}$ pathway is under selective pressure for deregulation of Akt, an event that may further facilitate astrocytoma development by a reduction in related apoptosis (Xiao et al., 2002). These cells exhibited similar growth and culture morphology characteristics in both earlier and later passages. It is speculated that 30 passages are insufficient to reach crisis and immortalization. The SV40 $\mathrm{T}$ antigen is known to interact with anti-oncogene products, such as p53 and Rb, and may be involved in deregulation of genes for proliferation and differentiation. This may lead to a loss of systemic dependence on growth factors, indication of autocrine loops, up-regulation of growth factor receptors, and resistance to apoptose (Tognon et al., 1996, Kim et al., 2001). Thus, midbrain tumor cells will be useful for further study of tumorigenesis, replenishment, and differentiation of astrocytes and neuronal cells (Figure 5).

The integration sites of the transgene may have contributed to the spatial distribution of the midbrain tumor. This cell line may also be valuable for study of midbrain tumorigenesis, replenishment, and differentiation of neural cells.

\section{Acknowledgement}

This work was supported in part by BioGreen21 (200203706), Republic of Korea.

\section{References}

Armstrong WE. Morphological and electrophysiological classification of hypothalamic supraoptic neurons. Prog Neurobiol 1995;47:291-339

Burbach JP, Luckman SM, Murphy D, Gainer H. Gene regulation in the magnocellular hypothalamo-neurohypophysial system. Physiol Rev 2001;81:1197-267

Chen SC, Vassileva G, Kinsley D, Holzmann S, Manfra D, Wiekowski MT, Romani N, Lira SA. Ectopic expression of the murine chemokines CCL21a and CCL21b induces the formation of lymph node-like structures in pancreas, but not skin, of transgenic mice. J Immunol 2002;168:1001-8

Dolcetti R, Martini F, Quaia M, Gloghini A, Vignocchi B, Cariati R, Martinelli M, Carbone A, Boiocchi M, Tognon M. Simian virus 40 sequences in human lymphoblastoid B-cell lines. J Virol 2003;77:1595-7

Gainer H, Fields RL, House SB. Vasopressin gene expression: experimental models and strategies. Exp Neurol 2001;171: 190-9

Hanahan D. Heritable formation of pancreatic beta-cell tumors in transgenic mice expressing recombinant insulin/simian virus 40 oncogenes. Nature 1985;315:115-22

Jeong SW, Castel M, Zhang BJ, Fields RL, Paras P, Arnheiter 
H, Chin H, Gainer H. Cell-specific expression and subcellular localization of neurophysin-CAT-fusion proteins expressed from oxytocin and vasopressin gene promoter-driven constructs in transgenic mice. Exp Neurol 2001;171:255-71

Kim HS, Shin JY, Yun JY, Ahn DK, Lee JY. Immortalization of human embryonic fibroblasts by overexpression of c-myc and simian virus 40 large T antigen. Exp Mol Med 2001;33:293-8

Lee JW, Park JH, Kim KS, Lee EJ, Kim MO, Kim SH, Jeong SW, Kim CW, Lee HJ, Kang KS, Chang KT, Hyun BH, Ryoo ZY. Vasopressin-SV40 T antigen expression in transgenic mice induces brain tumor and lymphoma. Biochem Biophys Res Commun 2003;302:785-92

Lu YJ, Guo SP, Tong T, Xu LH, Dong XY, Hana NJ, Cheng SJ. Establishment and characterization of a SV40T-transformed human bronchial epithelial cell line. Lung Cancer 1998;19: $15-24$

Mason WT, Hatton GI, Ho YW, Chapman C, Robinson IC. Central release of oxytocin, vasopressin and neurophysin by magnocellular neuron depolarization: evidence in slices of guinea pig and rat hypothalamus. Neuroendocrinology 1986; 42:311-22

McCarthy SA, Symonds HS, Van Dyke T. Regulation of apoptosis in transgenic mice by simian virus $40 \mathrm{~T}$ antigen-mediated inactivation of p53. Proc Natl Acad Sci USA 1994;91:3979-83

Messing A, Chen HY, Palmiter RD, Brinster RL. Peripheral neuropathies, hepatocellular carcinomas and islet cell adenomas in transgenic mice. Nature 1985;316:461-3

Montag AG, Oka T, Baek KH, Choi CS, Jay G, Agarwal K. Tumors in hepatobiliary tract and pancreatic islet tissues of transgenic mice harboring gastrin simian virus 40 large tumor antigen fusion gene. Proc Natl Acad Sci USA 1993;90: 6696-700

Park TS, Hoffman HJ, Hendrick EB, Humphreys RP, Becker LE. Medulloblastoma: clinical presentation and management. Experience at the hospital for sick children, toronto, 19501980. J Neurosurg 1983;58:543-52
Ratty AK, Jeong SW., Nagle JW, Chin H, Gainer H, Murphy D, Venkatesh B. A systematic survey of the intergenic region between the murine oxytocin- and vasopressin-encoding genes. Gene 1996;174:71-8

Ryoo ZY, Kim MO, Kim KE, Bahk YY, Lee JW, Park SH, Kim $\mathrm{JH}$, Byun SJ, Hwang HY, Youn J, Kim TY. Expression of recombinant human granulocyte macrophage-colony stimulating factor (hGM-CSF) in mouse urine. Transgenic Res 2001; 10:193-200

Schmitz E, Mohr E, Richter D. Rat vasopressin and oxytocin genes are linked by a long interspersed repeated DNA element (LINE): sequence and transcriptional analysis of LINE. DNA Cell Biol 1991;10:81-91

Seo YR, Jung HJ. The potential roles of p53 tumor suppressor in nucleotide excision repair (NER) and base excision repair (BER). Exp Mol Med 2004;36:505-9

Sladek TL, Jacobberger JW. Dependence of SV40 large T-antigen cell cycle regulation on T-antigen expression levels. Oncogene 1992;7:1305-13

Symonds HS, McCarthy SA, Chen J, Pipas JM, Van Dyke T. Use of transgenic mice reveals cell-specific transformation by a simian virus 40 T-antigen amino-terminal mutant. Mol Cell biol 1993;13:3255-65

Symonds H, Krall L, Remington L, Saenz-Robles M, Lowe S, Jacks T, Van Dyke T. p53-dependent apoptosis suppresses tumor growth and progression in vivo. Cell 1994;78:703-11

Tognon M, Casalone R, Martini F, De Mattei M, Granata P, Minelli E, Arcuri C, Collini P, Bocchini V. Large T antigen coding sequences of two DNA tumor viruses, BK and SV40, and nonrandom chromosome changes in two glioblastoma cell lines. Cancer Genet Cytogenet 1996;90:17-23

Yaginuma $Y$, Westphal $H$. Analysis of the $p 53$ gene in human uterine carcinoma cell lines. Cancer Res 1991;51:6506-9

Xiao A, Wu H, Pandolfi PP, Louis DN, Van Dyke T. Astrocyte inactivation of the $\mathrm{pRb}$ pathway predisposes mice to malignant astrocytoma development that is accelerated by PTEN mutation. Cancer Cell 2002;1:157-68 